\title{
Steam-PBL: Strategi Pengembangan Kemampuan Memecahkan Masalah Anak Usia Dini
}

\author{
Suci Utami Putri ${ }^{1}$, Abdurrohman Ahmad Taqiudin ${ }^{1}{ }^{\bowtie}$ \\ Pendidikan Guru Pendidikan Anak Usia Dini, Universitas Pendidikan Indonesia(1) \\ DOI: $\underline{10.31004 / \text { obsesi.v6i2.1270 }}$
}

\begin{abstract}
Abstrak
Penelitian ini bertujuan untuk mendeskripsikan proses STEAM-Project Based Learning (STEAM-PBL) serta mengidentifikasi perkembangan kemampuan pemecahan masalah selama kegiatan berlangsung. Pada penelitian ini digunakan mixed method concurrent embedded design yang mengombinasikan data kualitatif berupa deskripsi aktivitas belajar dan data kuantitatif terkait kemampuan pemecahan masalah anak yang diperoleh dengan menggunakan lembar observasi. Partisipan yang terlibat adalah 14 anak usia 5-6 tahun di salah satu TK di Kabupaten Purwakarta yang diamati selama satu bulan kegiatan penelitian berlangsung. Data aktivitas belajar dianalisis secara deskriptif sedangkan data perkembangan kemampuan memecahkan masalah dianalisis dengan menghitung jumlah dan persentase anak yang masuk ke dalam kriteria perkembangan tertentu. Hasil penelitian menunjukkan bahwa pembelajaran STEAMPBL di PAUD dilakukan melalui tahapan reflection, research, discovery, application dan communication. Sementara itu, kemampuan memecahkan masalah anak mengalami perkembangan yang semula pada umumnya berada pada kriteria "Belum berkembang" dan "Mulai Berkembang" meningkat menjadi "Berkembang Sesuai Harapan" dan "Berkembang Sangat Baik"'.
\end{abstract}

Kata Kunci: steam-pbl; kemampuan memecahkan masalah; anak usia dini.

\begin{abstract}
This study aims to describe the process of STEAM-Project Based Learning (STEAM-PBL) and identify the development of problem solving abilities during the activity. This study uses a mixed method concurrent embedded design that combines qualitative data in the form of descriptions of learning activities and quantitative data related to children's problem solving abilities obtained using observation sheets. The participants involved were 14 children aged 5-6 years in one of the kindergartens in Purwakarta who were observed for one month during the research activity. Learning activity data were analyzed descriptively while problem solving ability development data were analyzed by calculating the number and percentage of children who fit certain developmental criteria. The results showed that STEAM-PBL learning in PAUD was carried out through the stages of reflection, research, discovery, application and communication. Meanwhile, children's problem-solving skills have developed which were originally generally on the criteria of "Not yet developed" and "Starting to Develop" increased to "Developing according to expectations" and "Developing very well".
\end{abstract}

Keywords: STEAM-PBL; problem Solving Abilitiy; Early Childhood.

Copyright (c) 2021 Suci Utami Putri, Abdurrohman Ahmad Taqiudin

$\triangle$ Corresponding author:

Email Address : suciutami@upi.edu (Jawa Barat, Indonesia)

Received 24 February 2021, Accepted 23 June 2021, Published 18 July 2021

856 | Jurnal Obsesi: Jurnal Pendidikan Anak Usia Dini, 6(2), 2022 


\section{PENDAHULUAN}

Resistensi seorang individu dalam menghadapi permasalahan dapat dikembangkan sejak usia dini. Hal ini tentu saja didasarkan pada pandangan bahwa anak usia dini juga mengalami permasalahan dalam kehidupan sehari-hari. Masalah yang dihadapi oleh anak tentu akan berbeda dengan orang dewasa. Permasalahan yang dihadapi biasanya terjadi pada saat anak bermain bersama teman atau ketika melihat suatu objek dan peristiwa yang membuat anak merasa penasaran. Sebagian orang dewasa akan dengan sigap membantu anak ketika mereka menghadapi sebuah permasalahan. Hal tersebut justru akan membatasi perkembangan kemampuan memecahkan masalah yang akan tumbuh pada diri anak sehingga anak akan menjadi sangat ketergantungan pada orang dewasa di sekitarnya ketika akan menyelesaikan permasalahan. Membimbing anak untuk menemukan solusi dalam menyelesaikan masalah melalui kegiatan pengamatan, inkuiri, melakukan percobaan, berdiskusi atau bahkan kegiatan membaca merupakan cara yang tepat untuk dilakukan.

Indikator yang menunjukkan kemampuan pemecahan masalah pada anak dapat dilihat dari kemampuan mengamati, mengelompokkan, membandingkan, mengukur, mengomunikasikan, melakukan percobaan, menghubungkan, membuat kesimpulan dan menggunakan informasi (Wortham, 2006). Maria (Syaodih et al., 2018) mengatakan bahwa indikator kemampuan memecahkan masalah meliputi Observasi (observation), mengumpulkan data dan informasi (collecting), mengolah informasi (Analyze) dan mengomunikasikan informasi (communicating). Kedua pendapat tersebut dapat dijadikan rujukan untuk mengukur kemampuan pemecahan masalah pada anak usia dini.

Kemampuan memecahkan masalah merupakan kemampuan yang penting untuk dimiliki anak pada abad 21 (Md, 2019). Kemampuan memecahkan masalah tumbuh di usia dini dan akan berkembang serta berkontribusi pada kemampuan determinasi diri yaitu kemampuan untuk bertindak secara mandiri (Palmer et al., 2013). Selain untuk melatih kemampuan mencari solusi, kemampuan menyelesaikan masalah dapat berdampak pada perkembangan kemampuan lainnya seperti kemampuan berpikir kritis dan sistematis (Syaodih et al., 2018), kreatif (Shieh \& Chang, 2014), dan komunikasi (Dyah \& Setiawati, 2019). Pada pendapat lain, dikatakan bahwa kemampuan memecahkan masalah bermanfaat untuk anak ketika mengeksplorasi dunianya atau saat anak mengerjakan tugasnya di sekolah (L. D. Lestari, 2020).

Berdasarkan berbagai pendapat di atas, maka stimulasi kepada anak usia dini untuk menumbuhkan kemampuan memecahkan masalah sangat penting untuk dilakukan. Stimulasi perkembangan kemampuan memecahkan masalah pada anak dapat dilakukan melalui kegiatan pembelajaran yang menghadirkan masalah sebagai basis utamanya. Masalah yang disajikan kepada anak harus bersifat terbuka (open-ended) sehingga memungkinkan anak menemukan jawaban atau solusi yang bervariasi.

Salah satu kegiatan belajar yang dapat menstimulasi kemampuan pemecahan masalah anak yaitu melalui STEAM-PBL. STEAM-PBL merupakan kombinasi antara pendekatan STEAM dengan model project based learning. STEAM berkembang dari STEM dengan penambahan unsur "Art" di dalamnya. Unsur seni atau "Art" berkontribusi terhadap: 1) kemampuan berpikir yang meliputi kegiatan menalar, intuisi, persepsi, imajinasi, kreativitas, problem solving; 2) kemampuan sosial yang meliputi kepercayaan diri, pengendalian diri, resolusi konflik, kolaborasi, empati dan toleransi; 3) motivasi untuk belajar dengan indikasi keterlibatan aktif, perhatian lebih, persisten dan berani mengambil resiko (Sompayrac, 2002). Robelen mengatakan bahwa kehadiran unsur seni di dalam STEAM tidak hanya dapat meningkatkan keterlibatan anak dalam pembelajaran, tetapi juga dapat mengembangkan kemampuan berpikir kreatif dan inovatif (DeJarnette, 2018). Dari pendapat tersebut, dapat disimpulkan bahwa unsur seni menambah kekayaan STEM dalam mengembangkan kemampuan anak usia dini. Hal ini tentu saja menjadikan STEM atau STEAM sebagai salah satu pendekatan terkini yang dapat diterapkan dalam Pendidikan Anak Usia Dini. 
Pada beberapa penelitian terdahulu, penerapan STEM/STEAM seringkali diintegrasikan dengan pembelajaran berbasis proyek atau project based learning. Integrasi project based learnig di dalam STEM/STEAM secara efektif dapat meningkatkan motivasi belajar, pemahaman anak terhadap materi pembelajaran, kemampuan kolaboratif, kreativitas, literasi sains dan kemampuan komunikasi (Astuti et al., 2019; Lely et al., 2020; Lutfi et al., 2017; Nopiyanti et al., 2020; Putri, 2019). Integrasi project based learning ke dalam STEM/STEAM merupakan perpaduan yang sempurna karena memiliki karakteristik yang hampir sama yaitu bersifat kontekstual dan lintas disiplin ilmu, berorientasi pada pemecahan masalah (Miller, 2017). Kombinasi STEAM dan Project Based Learning menghasilkan strategi pembelajaran yang potensial dalam menstimulus aspek perkembangan anak.

Implementasi STEAM-PBL untuk PAUD dilaksanakan melalui langkah-langkah berikut: 1) reflection, tahap di mana anak mengasimilasi apa yang akan dipelajari dengan apa yang telah diketahui; 2) research, yaitu kegiatan mengumpulkan informasi yang diperlukan untuk menyelesaikan project, pada tahap ini guru dapat mengajukan permasalahan yang harus diselesaikan oleh siswa; 3) discovery, yaitu tahap dimana siswa merumuskan atau menemukan solusi penyelesaian masalah ; 4) application, yaitu kegiatan merancang dan merevisi model atau produk sebagai solusi dari masalah; dan 5) communication, yaitu mempresentasikan model atau produk yang telah dibuat (Laboy-Rush, 2021). Dari tahapan tersebut, dapat disimpulkan bahwa pembelajaran STEAM-PBL memberikan kesempatan untuk bereksplorasi, berkolaborasi dan berinovasi dalam rangka menyelesaikan masalah. Karakteristik pembelajaran STEAM tersebut dapat menstimulus perkembangan anak mengembangkan kemampuan mengolah informasi dan berkomunikasi (Dewi et al., 2016; Nopiyanti et al., 2020)

Penerapan STEAM-PBL di Indonesia pada jenjang PAUD masih sangat jarang dilakukan. Salah satu penelitian tentang STEAM-PBL yang telah dilakukan yaitu penelitian pengembangan model pembelajaran sains berbasis STEAM-PBL pada tema-tema Islami (Imaduddin, 2017). Sebagian besar penelitian tentang penerapan STEAM dan project based learning dilakukan secara terpisah tanpa mengintegrasikannya satu sama lain. Beberapa penelitian tentang STEAM untuk PAUD dilakukan secara kualitatif untuk mendeskripsikan karakteristik implementasi dan pengembangan kurikulum berbasis STEAM (Munawar et al., 2019; Wahyuni et al., 2020). Dalam penelitian STEAM lainnya, diperoleh hasil bahwa penerapan STEAM di PAUD berpotensi untuk meningkatkan kreativitas anak (Wahyuningsih et al., 2020). Di sisi lain, hasil penelitian tentang project based learning untuk PAUD menujukkan bahwa penerapan project based learning dapat mensitmulus perkembangan kemampuan motorik, kemampuan kerjasama, dan keterampilan prososial (Herawati et al., 2020; S. Lestari et al., 2016; Maulidah et al., 2018). Minimnya penelitian tentang penerapan STEAM-PBL di PAUD serta potensi pembelajaran STEAM dan project based learning dalam mengembangkan kemampuan anak menjadi dasar kuat untuk melaksanakan penelitian tentang penerapan STEAM-PBL. Untuk itu, dalam artikel ini akan dipaparkan hasil penelitian tentang STEAMPBL di PAUD yang diharapkan dapat memberikan gambaran mengenai proses penerapan serta efektivitasnya dalam perkembangan kemampuan memecahkan masalah anak usia dini.

\section{METODOLOGI}

Penelitian ini menggunakan pendekatan mixed method dengan concurrent embedded design (Sugiyono, 2011) yang mengombinasikan data kualitatif (data primer) berupa deskripsi proses pembelajaran STEAM-PBL di PAUD untuk menstimulus perkembangan kemampuan pemecahan masalah anak yang ditunjang dengan data kuantitatif (data sekunder) berupa data perkembangan kemampuan memecahkan masalah anak yang terlibat dalam penelitian ini. Metode penelitian ini dipilih karena diyakini dapat membantu peneliti mengungkap hal-hal secara lengkap dan utuh terkait aktivitas yang dilakukan oleh guru dan anak secara detail serta perkembangan yang ditunjukkan oleh anak sebagai dampak dari pemberian perlakuan 
pembelajaran dengan menggunakan STEAM-PBL. Gambaran pelaksanaan penelitian dengan desain concurrent embedded pada penelitian mixed method ini dapat dilihat pada Gambar 1 .

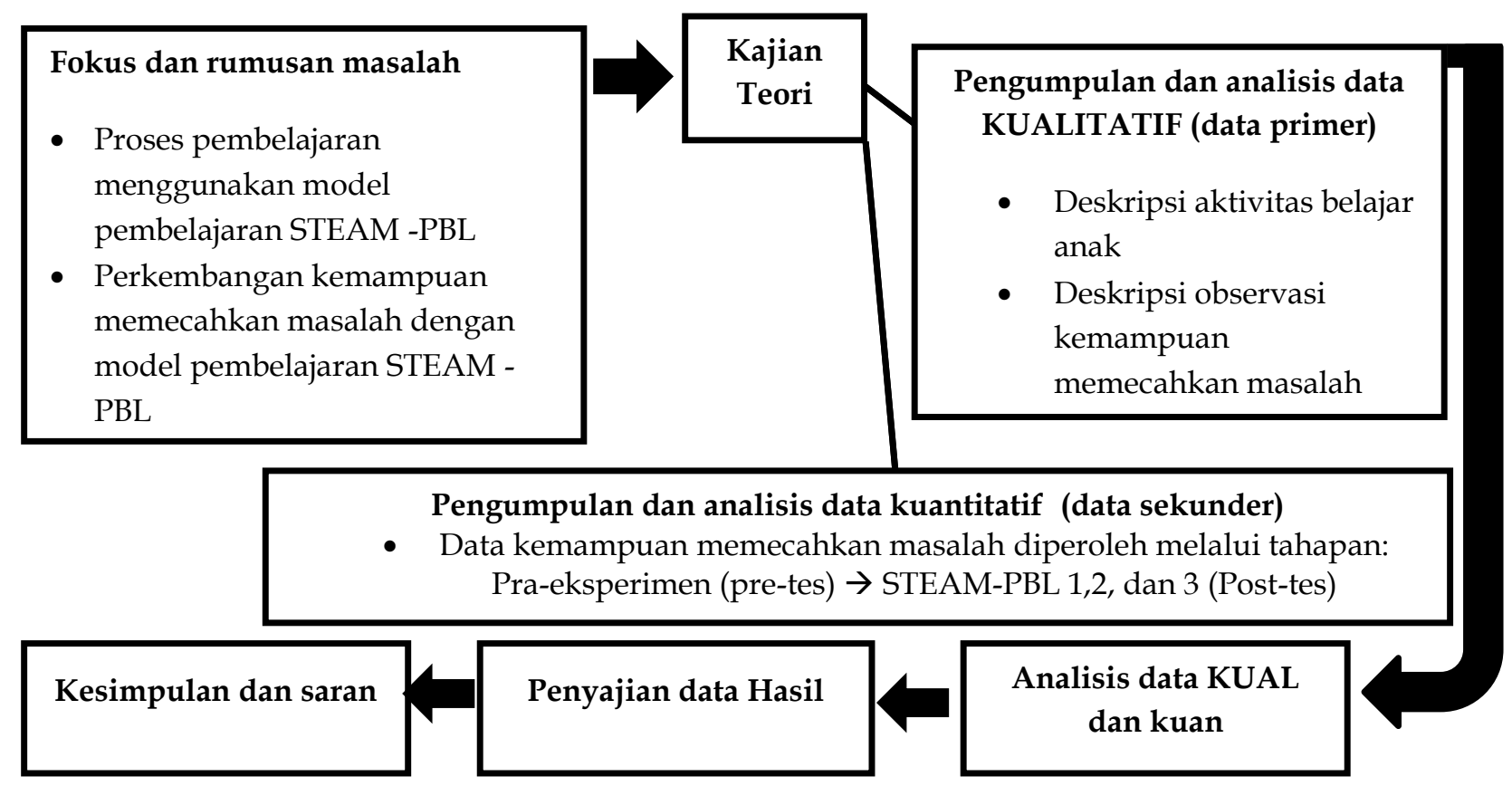

Gambar 1. Proses pelaksanaan penelitian dengan menggunakan mixed method concurrent embedded design

Pada penelitian ini dilibatkan 14 anak di salah satu TK Kabupaten Purwakarta dengan rentang usia 5-6 tahun. Data diperoleh melalui teknik observasi dengan menggunakan instrumen penelitian yang terdiri dari: 1) lembar observasi aktivitas guru dan anak pada setiap tahap kegiatan STEAM-PBL yang terdiri dari reflection, research, discovery, application, communication (Laboy-Rush, 2021); 2) lembar observasi kemampuan memecahkan masalah yang merujuk pada indikator kemampuan memecahkan masalah menurut Maria (Syaodih et al., 2018) yang meliputi kemampuan : 1) mengamati; 2) mengumpulkan data; 3) mengolah informasi; dan 4) mengomunikasikan hasil; dan 3) dokumentasi berupa rekaman video pembelajaran yang digunakan untuk membantu melengkapi kekurangan data hasil observasi aktivitas anak dan guru selama proses pembelajaran. Instrumen penelitian yang digunakan telah melalui proses validasi oleh dua orang expert yang terdiri dari expert pembelajaran sains untuk anak usia dini dan expert pendidikan anak usia dini.

Data hasil observasi berupa data aktivitas guru dan anak dipaparkan secara deskriptif pasa setiap rangkaian pembelajaran STEAM yang dilakukan mulai dari STEAM-PBL 1, 2 dan 3. Sementara itu, perkembangan kemampuan pemecahan masalah setiap anak diidentifikasi pada kriteria tertentu untuk kemudian dihitung jumlah anak yang masuk ke dalam kriteria yang terdiri dari: Belum Berkembang (BB), Mulai Berkembang (MB), Berkembang Sesuai Harapan (BSH) dan Berkembang Sangat Baik (BSB). Rekapitulasi jumlah anak tersebut selanjutnya dianalisis secara statistik deskriptif dengan menghitung persentase jumlah anak yang masuk pada kriteria tertentu dengan menggunakan rumus sebagai berikut.

$$
\mathrm{p}=\frac{f}{n} \times 100 \%
$$

Keterangan:

$\mathrm{p} \quad=$ persentase anak dengan kriteria perkembangan tertentu

$\mathrm{f} \quad=$ frekuensi/ jumlah anak yang masuk ke dalam kriteria perkembangan tertentu

$\mathrm{n}=$ jumlah total anak 


\section{HASIL DAN PEMBAHASAN}

Tujuan utama dalam penelitian ini adalah mendeskripsikan proses pembelajaran dengan menggunakan STEAM-PBL untuk PAUD dan mengidentifikasi perkembangan kemampuan pemecahan masalah anak selama proses pembelajaran berlangsung. Berdasarkan tujuan utama tersebut, maka pemaparan hasil dan pembahasan pada bagian ini akan dijelaskan sebagai berikut.

\section{Deskripsi Proses Pembelajaran STEAM-PBL}

Kegiatan pembelajaran STEAM-PBL pada penelitian ini dilakukan sebanyak tiga kali rangkaian yang terdiri dari: 1) STEAM-PBL 1: kegiatan membuat gedung untuk kantor; 2) STEAM-PBL 2: membuat kandang untuk hewan-hewan ternak; dan 3) STEAM-PBL 3: membuat wayang. Setiap rangkaian kegiatan STEAM-PBL tersebut memiliki tahapan pembelajaran yang meliputi reflection, research, discovery, application, dan communication yang dapat dideskripsikan sebagai berikut.

\section{Reflection}

Tahap ini merupakan kegiatan yang bertujuan untuk mengidentifikasi pengetahuan awal anak mengenai tema yang akan dipelajari. Metode yang digunakan guru pada tahap ini adalah metode bercakap-cakap, metode bercerita atau metode tanya jawab. Pada STEAM-PBL 1 , anak dan guru bercakap-cakap tentang suasana perkotaan yang sangat padat, banyak sekali gedung-gedung tinggi, kendaraan serta kemacetan di jalan-jalan. Pada STEAM-PBL 2, anak sangat antusias menceritakan pengalamannya ketika berkunjung ke desa tempat tinggal nenek atau kerabatnya. Pada STEAM-PBL 3, guru melakukan tanya jawab tentang permainanpermainan tradisional apa yang sering dimainkan oleh anak, alat yang digunakan apa dan bagaimana cara memainkannya. Kegiatan ini memunculkan rasa senang anak untuk memulai pembelajaran dan menghubungkan pengetahuan anak dengan tema yang akan dipelajari.

\section{Research}

Kegiatan mengeksplorasi informasi tentang tema yang akan dipelajari atau proyek yang akan dibuat serta penyajian masalah yang bersifat open-ended merupakan kegiatan inti dari tahap ini. Pada STEAM-PBL 1, anak diajak mengamati berbagai bentuk gedung perkantoran beserta ruangan-ruangannya melalui video pembelajaran dilanjutkan dengan proses tanya jawab tentang isi video. Setelah menyimak video, guru bercerita tentang seorang pengusaha bernama pak Eko yang belum memiliki kantor untuk perusahaannya di kota lalu guru mengajukan pertanyaan berikut: "Maukah teman-teman buatkan gedung untuk kantor pak eko?", "gedung seperti apa yang akan teman-teman buatkan untuk Pak Eko?". Pada STEAMPBL 2, anak diajak mengamati gambar suasana peternakan yang ada di desa lalu bertanya jawab tentang tentang hal-hal yang terdapat pada gambar. Setelah mengamati gambar, guru bercerita tentang seorang peternak bernama pak Mail yang memiliki banyak hewan ternak tapi pak Mail hanya memiliki sedikit kandang untuk hewan ternaknya. Cerita ini mengantarkan anak pada masalah yang disajikan dalam bentuk pertanyaan berikut : "Dapatkah teman-teman membantu pak Mail membuat kandang untuk hewan ternaknya?, kandang seperti apa yang akan teman-teman buatkan?". Pada STEAM-PBL 3, anak diajak mengamati berbagai bentuk wayang sebagai salah satu alat permainan tradisional melalui video pembelajaran yang dilanjutkan dengan kegiatan tanya jawab tentang isi video. Setelah itu, guru bercerita tentang seorang anak raja yang gemar sekali bermain wayang, namun pada suatu saat wayang milik anak raja tersebut rusak yang membuatnya menjadi sangat sedih. Cerita ini mengantarkan anak pada masalah yang disajikan dalam bentuk pertanyaan berikut : "Maukah teman-teman membuatkan wayang baru untuk anak raja?, wayang seperti apa yang akan teman-teman buatkan?". Pertanyaan-pertanyaan yang disajikan pada tahap ini merupakan trigger untuk anak memulai imajinasinya dalam membuat desain proyek yang akan diselesaikan secara berkelompok. Oleh karena itu, pada tahap ini guru harus mencari 
cara yang tepat untuk meramu pertanyaan ke dalam bentuk cerita yang menarik dan sangat kontekstual untuk anak.

\section{Discovery}

Pada tahap ini, anak bersama-sama dengan kelompoknya membuat gambar tentang proyek yang akan dibuatnya (STEAM-PBL 1 membuat gambar gedung, STEAM-PBL2 membuat gambar kandang untuk hewan ternak, STEAM-PBL3 membuat gambar wayang). Gambar yang dibuat oleh anak terinspirasi dari kegiatan pengamatan yang dilakukan pada tahap "research" ditambah dengan imajinasi yang dimiliki. Kondisi pembelajaran pada tahap ini sangat ramai karena setiap anak mencoba untuk mengemukakan idenya ke dalam gambar dan berharap idenya diterima oleh anggota kelompok lainnya. Guru perlu melakukan pemantauan dan bimbingan intensif kepada setiap kelompok agar mereka bersepakat tentang ide atau gagasan siapa yang akan diterima dan dimasukkan ke dalam gambar. Setelah membuat gambar, anak bersama-sama dengan kelompoknya memilih alat dan bahan yang diperlukan untuk membuat proyek yang akan diselesaikan. Pada kegiatan ini, anak bebas memilih alat dan bahan yang diperlukan sesuai dengan imajinasi dan kesepakatan bersama kelompoknya. Guru memfasilitasi anak dengan menyediakan berbagai alat dan bahan yang kemungkinan akan digunakan oleh anak. Beberapa contoh desain gambar yang dibuat anak dapat dilihat pada Gambar 2.
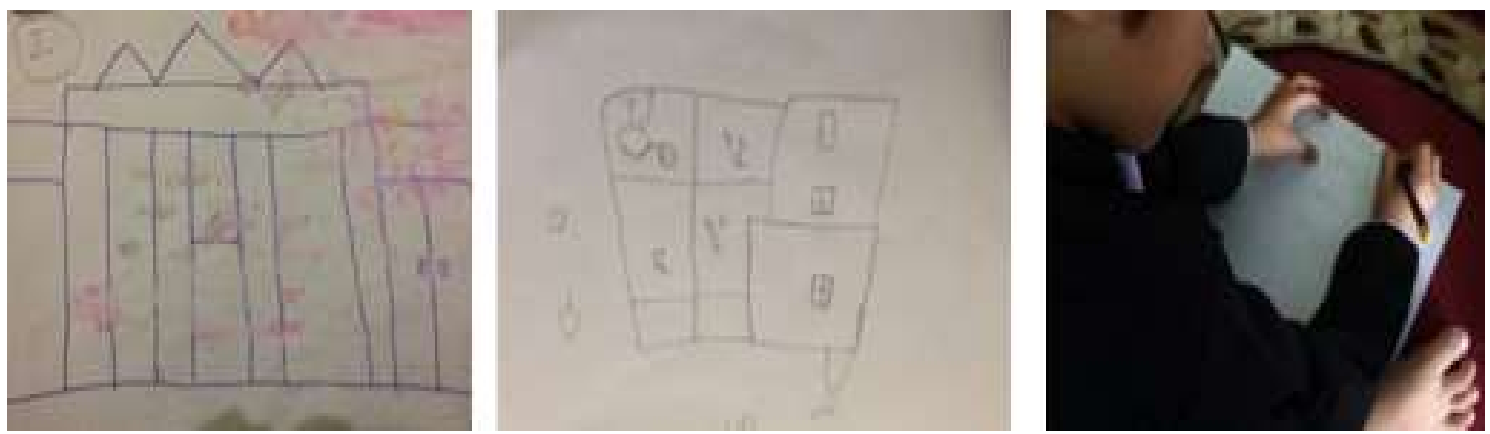

Gambar 2. Gambar desain kantor yang dibuat anak

(Sumber: dokumen pribadi, 2019)

\section{Application}

Pada tahap ini anak bersama dengan kelompoknya berkerjasama menyelesaikan proyek dengan menggunakan alat dan bahan yang telah dipilih. Anak sangat antusias dalam membuat proyek dan seringkali beradu argument antara anggota yang satu dengan yang lainnya. Hal ini sangat lumrah untuk anak usia dini yang memiliki sifat egosentris. Guru berkewajiban untuk membimbing anak dalam menyepakati hal-hal yang menjadi polemik dengan memberikan gambaran tentang keputusan apa yang tepat untuk diambil. Kegiatan lainnya pada tahap ini yang sangat penting adalah anak melakukan uji coba proyek yang telah dibuatnya, missal: 1) STEAM-PBL1, guru meminta anak meletakkan gedung yang telah dibuatnya secara horizontal. Jika gedung berdiri tegak dan tak terlihat miring maka anak tidak perlu melakukan perbaikan, namun jika gedung terlihat miring maka anak diminta untuk memperbaikinya; 2) STEAM-PBL2, anak diminta memasukkan beberapa mainan hewanhewan ternak. Anak diminta membandingkan apakah kandang sapi ukurannya lebih kecil dengan kandang ayam, jika lebih kecil maka guru menyampaikan bahwa nanti sapi akan kesulitan bergerak dan meminta anak memperbesar kandang untuk sapi; dan 3) STEAMPBL3, anak diminta memainkan wayang yang telah dibuatnya, jika wayang terlihat terkulai atau tidak kokoh, maka anak diminta untuk memperbaiki. Kegiatan tersebut melatih anak untuk terbiasa merefleksi, mengevaluasi dan memperbaiki kekeliruan-kekeliruan yang dilakukan sebelumnya. Gambar 3 kegiatan membuat proyek pada setiap pembelajaran STEAM-PBL. 

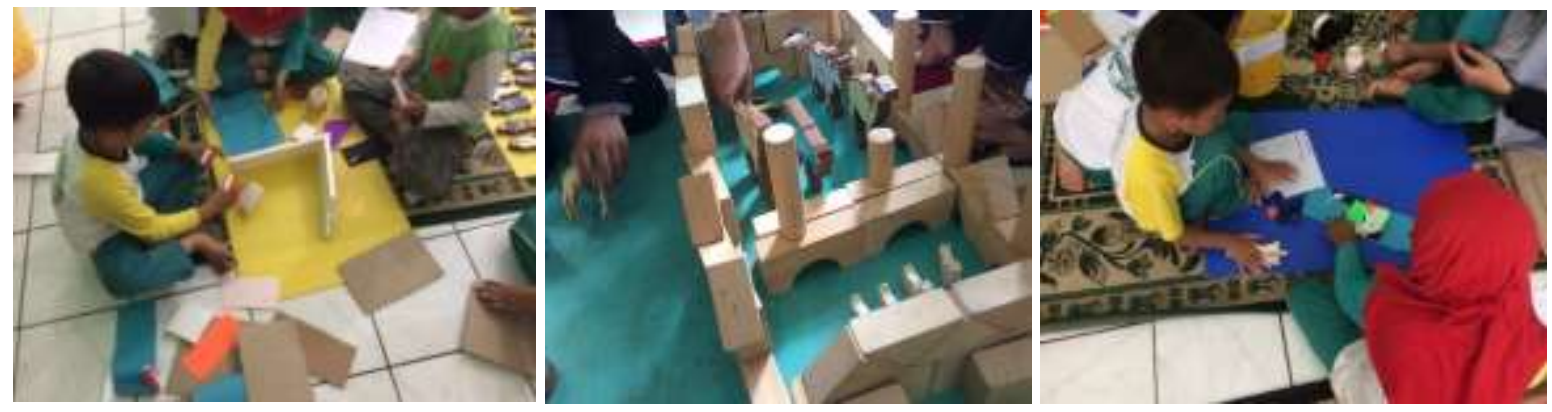

Gambar 3. Proses membuat, menyelesaikan dan menguji coba proyek

(Sumber: dokumen pribadi, 2019)

\section{Communication}

Pada tahap ini, setiap kelompok diminta untuk menceritakan tentang proyek yang telah diselesaikan kepada teman-teman di kelas. Setiap anggota kelompok diminta berbicara bergiliran untuk menjelaskan bagian-bagian yang ada pada proyek yang telah dibuatnya. Hal ini dilakukan untuk melatih kemampuan berbicara anak sehingga anak yang tadinya pasif menjadi termotivasi dan percaya diri untuk tampil di hadapan teman-temannya.

\section{Perkembangan Kemampuan Pemecahan Masalah Anak pada pembelajaran STEAM-PBL}

Pemaparan perkembangan kemampuan memecahkan masalah anak pada bagian ini akan diawali dengan data kemampuan awal anak sebelum kegiatan pembelajaran STEAMPBL dilaksanakan. Hal ini bertujuan agar peningkatan perkembangan anak dapat terlihat dengan jelas antara sebelum dan pada setiap kegaitan STEAM-PBL yang dilaksanakan. Data perkembangan kemampuan pemecahan masalah anak pada bagian ini akan dipaparkan berdasarkan indikator yang terdapat di dalam kemampuan memecahkan masalah anak yang terdiri dari indikator mengobservasi, mengumpulkan informasi, mengolah informasi dan mengomunikasikan.

\section{Data perkembangan anak pada indikator kemampuan mengobservasi}

Tabel 1. Data perkembangan kemampuan anak dalam melakukan observasi

\begin{tabular}{cccccc}
\hline No & $\begin{array}{c}\text { Inisial } \\
\text { nama } \\
\text { partisipan }\end{array}$ & \multicolumn{4}{c}{ Keterampilan observasi/mengamati } \\
\hline 1. & PB & BB & BB & MB & BSs \\
2. & RF & BB & BB & MB & BSB \\
3. & SN & MB & MB & BSH & BSB \\
4. & RY & BB & MB & BSH & BSB \\
5. & WR & MB & MB & MB & BSB \\
6. & AM & BB & BB & BSH & BSB \\
7. & RJ & BB & MB & MB & BSB \\
8. & ZM & BB & BB & BSH & BSB \\
9. & AT & MB & MB & MB & BSH \\
10. & KY & MB & BB & BSH & BSB \\
11. & YL & MB & MB & BSB & BSB \\
12. & AF & MB & MB & BSH & BSH \\
13. & IQ & BB & MB & BSH & BSH \\
14. & BY & MB & MB & BSH & BSB \\
\hline
\end{tabular}

Data pada Tabel 1 dilakukan analisis lebih lanjut dengan menghitung jumlah anak yang masuk kepada kriteria BB, MB, BSH, dan BSB untuk kemudian dilakukan penghitungan 
DOI: $10.31004 /$ obsesi.v6i2.1270

persentase. Persentase jumlah anak pada setiap kriteria dan pada setiap rangkatan kegiatan pembelajaran dapat dilihat pada Gambar 4.

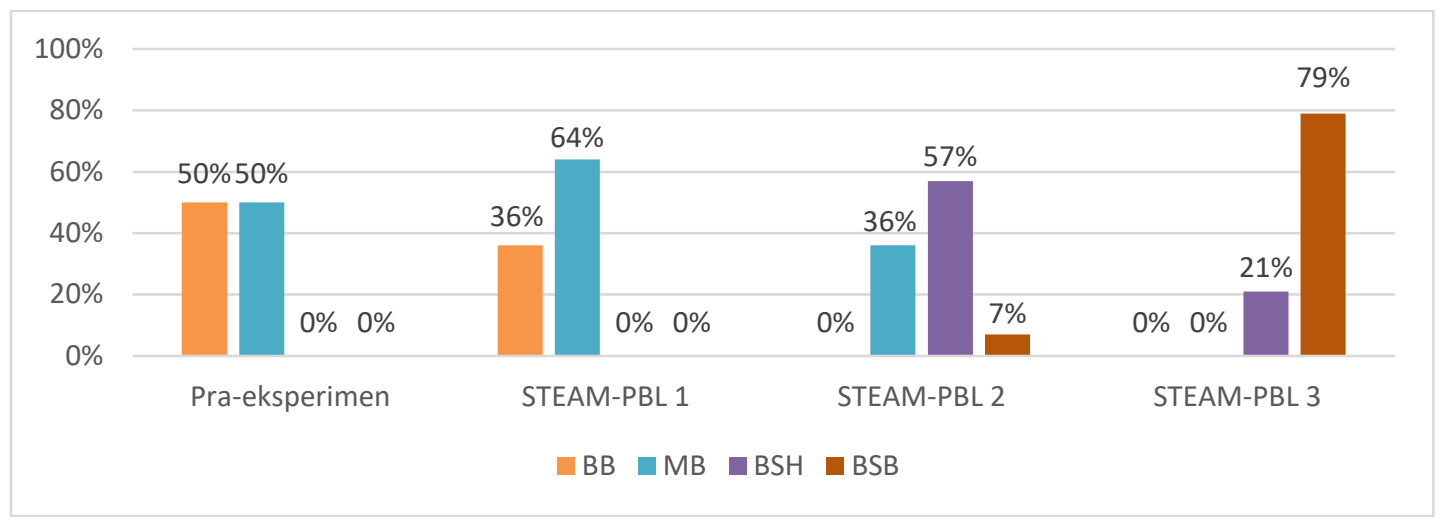

Gambar 4. Persentase jumlah anak pada kriteria tertentu untuk indikator mengobservasi

\section{Data perkembangan anak pada indikator kemampuan mengumpulkan informasi}

Data pada Tabel 2 dilakukan analisis lebih lanjut dengan menghitung jumlah anak yang masuk kepada kriteria BB, MB, BSH, dan BSB untuk kemudian dilakukan penghitungan persentase. Persentase jumlah anak pada setiap kriteria dan pada setiap rangkatan kegiatan pembelajaran dapat dilihat pada Gambar 5.

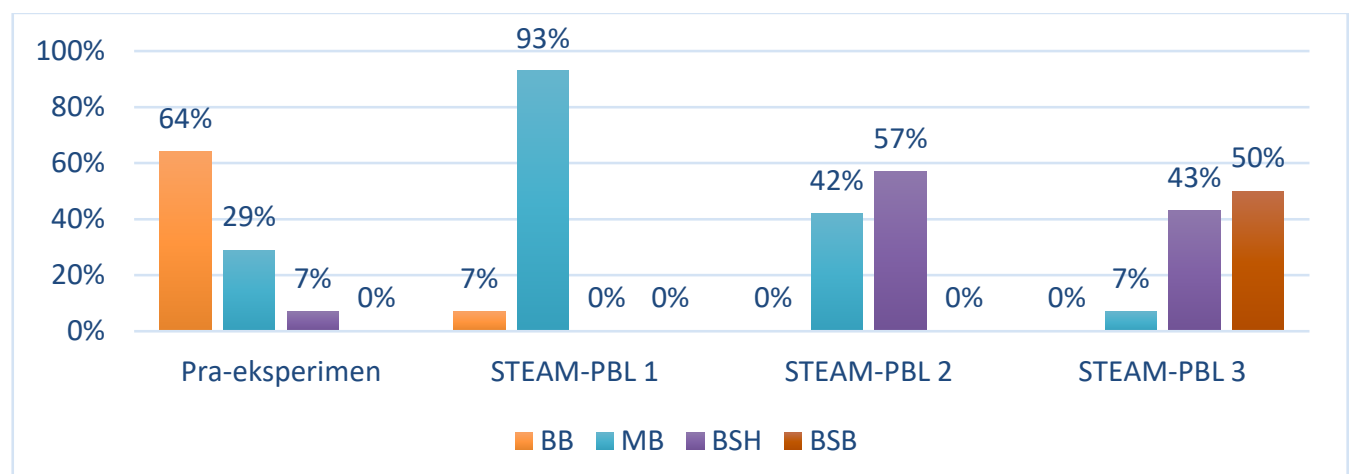

Gambar 5. Persentase jumlah anak pada kriteria tertentu untuk indikator mengumpulkan informasi

Tabel 2. Data perkembangan kemampuan anak dalam mengumpulkan informasi

\begin{tabular}{cccccc}
\hline \multirow{2}{*}{ No } & Nama & \multicolumn{4}{c}{ Keterampilan mengumpulkan informasi } \\
& anak & Pra-eksperimen & STEAM-PBL1 & STEAM-PBL2 & STEAM-PBL3 \\
\hline 1. & GB & BB & MB & MB & BSB \\
2. & RF & BB & MB & MB & BSB \\
3. & SN & BB & MB & BSH & BSH \\
4. & RY & BB & MB & BSH & BSB \\
5. & WR & MB & MB & MB & BSB \\
6. & AM & BB & MB & BSH & BSB \\
7. & RJ & MB & MB & MB & BSB \\
8. & ZM & BSH & MB & BSH & BSB \\
9. & AT & BB & MB & MB & MB \\
10. & KY & BB & BB & BSH & BSH \\
11. & YL & BB & MB & BSH & BSH \\
12. & AF & MB & MB & BSH & BSH \\
13. & IQ & BB & MB & MB & BSH \\
14. & BY & MB & MB & BSH & BSH \\
\hline
\end{tabular}




\section{Data perkembangan anak pada indikator kemampuan mengolah informasi}

Tabel 3. Data perkembangan kemampuan anak dalam mengolah informasi

\begin{tabular}{cccccc}
\hline \multirow{2}{*}{ No } & $\begin{array}{c}\text { Nama } \\
\text { anak }\end{array}$ & Pra-eksperimen & STEAM-PBL1 & STEAM-PBL2 & STEAM-PBL3 \\
\hline 1. & GB & BB & MB & MB & BSB \\
2. & RF & BB & MB & MB & BSB \\
3. & SN & BB & MB & MB & BSH \\
4. & RY & BB & MB & MB & BSB \\
5. & WR & MB & MB & BSH & BSB \\
6. & AM & BB & MB & MB & BSB \\
7. & RJ & BB & MB & BSH & BSB \\
8. & ZM & BB & BB & BSH & BSH \\
9. & AT & BB & MB & MB & BSH \\
10. & KY & BB & MB & MB & BSH \\
11. & YL & MB & MB & MB & MB \\
12. & AF & BB & BB & MB & MB \\
13. & IQ & BB & BB & MB & BSH \\
14. & BY & MB & MB & BSH & BSB \\
\hline
\end{tabular}

Data pada Tabel 3 dilakukan analisis lebih lanjut dengan menghitung jumlah anak yang masuk kepada kriteria BB, MB, BSH, dan BSB untuk kemudian dilakukan penghitungan persentase. Persentase jumlah anak pada setiap kriteria dan pada setiap rangkatan kegiatan pembelajaran dapat dilihat pada Gambar 6.

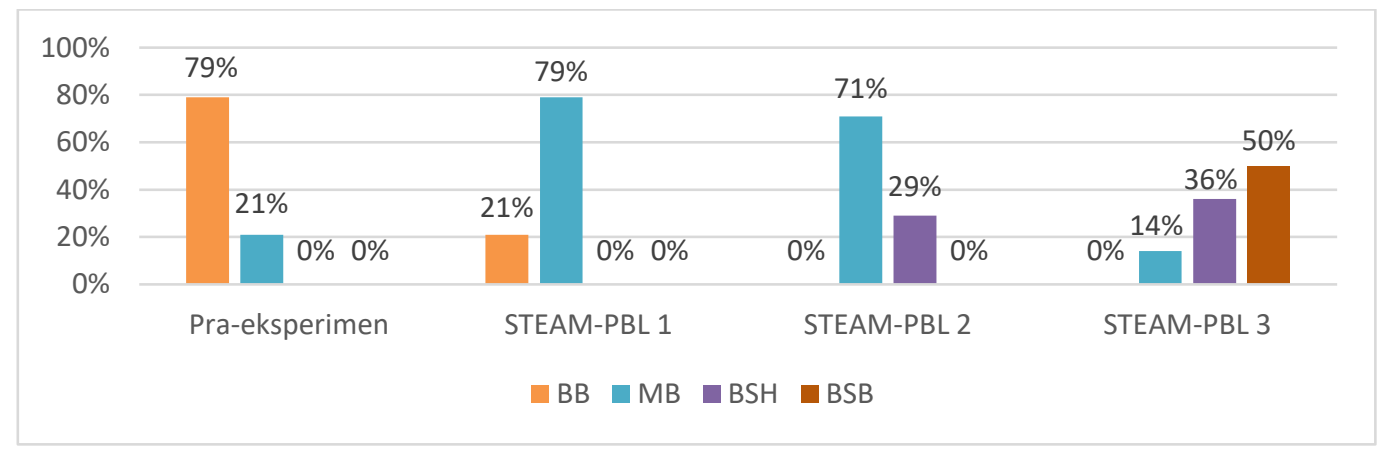

Gambar 6. persentase jumlah anak pada kriteria tertentu untuk indikator mengolah informasi

\section{Data perkembangan anak pada indikator kemampuan mengomunikasikan}

Data pada Tabel 4 dilakukan analisis lebih lanjut dengan menghitung jumlah anak yang masuk kepada kriteria BB, MB, BSH, dan BSB untuk kemudian dilakukan penghitungan persentase. Persentase jumlah anak pada setiap kriteria dan pada setiap rangkatan kegiatan pembelajaran dapat dilihat pada Gambar 7.

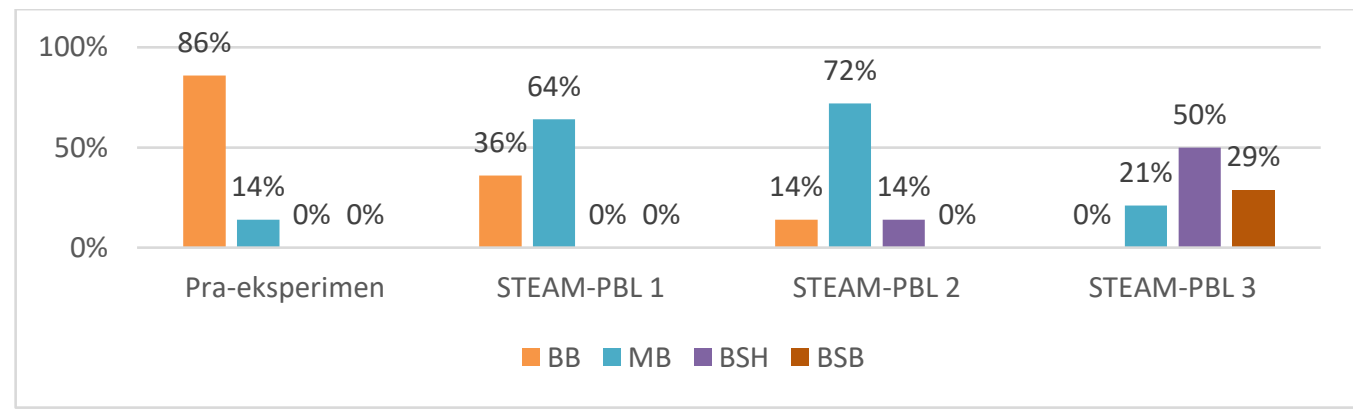

Gambar 7. persentase jumlah anak pada kriteria tertentu untuk indikator mengomunikasikan 
Tabel 4. Data perkembangan kemampuan anak pada indikator mengomunikasikan

\begin{tabular}{|c|c|c|c|c|c|}
\hline \multirow{2}{*}{ No } & \multirow{2}{*}{$\begin{array}{c}\text { Nama } \\
\text { anak }\end{array}$} & \multicolumn{4}{|c|}{ Keterampilan mengolah informasi } \\
\hline & & Pra-eksperimen & STEAM-PBL1 & STEAM-PBL2 & STEAM-PBL3 \\
\hline 1. & GB & $\overline{\mathrm{BB}}$ & MB & MB & BSB \\
\hline 2. & RF & BB & MB & MB & BSB \\
\hline 3. & SN & BB & MB & MB & BSH \\
\hline 4. & RY & BB & MB & $\mathrm{MB}$ & BSB \\
\hline 5. & WR & MB & $\mathrm{MB}$ & $\mathrm{BSH}$ & BSB \\
\hline 6. & $\mathrm{AM}$ & BB & $\mathrm{MB}$ & $\mathrm{MB}$ & BSB \\
\hline 7. & RJ & BB & $\mathrm{MB}$ & $\mathrm{BSH}$ & BSB \\
\hline 8. & $\mathrm{ZM}$ & BB & BB & BSH & BSH \\
\hline 9. & AT & BB & $\mathrm{MB}$ & $\mathrm{MB}$ & $\mathrm{BSH}$ \\
\hline 10. & KY & BB & $\mathrm{MB}$ & $\mathrm{MB}$ & $\mathrm{BSH}$ \\
\hline 11. & YL & MB & $\mathrm{MB}$ & $\mathrm{MB}$ & $\mathrm{MB}$ \\
\hline 12. & $\mathrm{AF}$ & BB & BB & MB & MB \\
\hline 13. & IQ & BB & BB & MB & BSH \\
\hline 14. & BY & MB & $\mathrm{MB}$ & $\mathrm{BSH}$ & BSB \\
\hline
\end{tabular}

Hasil penelitian di atas menunjukkan bahwa proses kegiatan belajar di dalam tahapan STEAM-PBL berpengaruh terhadap perkembangan kemampuan menyelesaikan masalah pada setiap indikator. Untuk menginisiasi kegiatan belajar, guru perlu mengundang dan menarik perhatian anak dalam rangka mengaktivasi pengetahuan awal yang dimiliki tentang tema pembelajaran sebagaimana yang dilakukan pada tahap reflection. Hal ini perlu untuk dilakukan agar anak memiliki motivasi belajar yang tinggi dan memudahkan guru mengarahkan anak dalam kegiatan selanjutnya. Pada tahap research, guru membuat cerita yang bersifat kontekstual, sesuai tema dan mudah dipahami anak. Cerita ini mengantarkan pada permasalahan yang yang disampaikan dalam bentuk pertanyaan yang bersifat openended, menantang dan langsung terkait dengan proyek sehingga anak akan lebih mudah mencerna dan menyelesaikan permasalahan dengan tepat (Aldabbus, 2018). Selain itu, tahap reflection dan research pada kegiatan STEAM-PBL yang bersifat eksploratif terhadap objek atau peristiwa terkait tema pembelajaran dapat memberikan kesempatan pada anak untuk melakukan pengamatan, mengumpulkan serta mengolah informasi sebagai bagian dari kegiatan menalar (Sompayrac, 2002).

Selain kegiatan yang bersifat eksploratif, pembelajaran kolaboratif merupakan sifat dominan lainnya di dalam STEAM-PBL. Kegiatan kolaboratif dapat memicu tumbuhnya kemampuan berpikir kritis anak yang diperlukan pada saat mengolah informasi (Dewi et al., 2016). Kegiatan belajar yang interaktif dan komunikatif pada saat anak berkolaborasi dengan kelompoknya dapat menstimulus perkembangan bahasa sebagai salah satu indikator perkembangan kemampuan komunikasi anak (Nopiyanti et al., 2020). Dalam penelitian ini, integrasi metode bercakap-cakap dan bercerita yang dilakukan pada tahap reflection, discovery, dan communication di dalam STEAM-PBL juga dapat membantu memunculkan keberanian pada diri anak untuk membangun hubungan (berkomunikasi) dengan guru dan teman lainnya pada saat kegiatan belajar (Mike \& Permila, 2012), membantu anak mengungkapkan bahasa secara tepat yang akan berdampak pada kemampuan komunikasi yang dimilikinya (Hadi G K, 2018), serta meningkatkan kemampuan anak untuk menceritakan sesuatu dengan kalimat sederhana (Nurjanah \& Anggraini, 2020). Pendapat tersebut menguatkan hasil penelitian bahwa STEAM-PBL sangat berpengaruh pada kemampuan komunikasi sebagai salah satu indikator kemampuan memecahkan masalah yang diukur. 


\section{SIMPULAN}

Aktivitas belajar STEAM-PBL untuk PAUD dilakukan melalui tahap reflection, research, discovery, application, dan communication. Adanya kesempatan yang leluasa pada anak untuk menuangkan ide, gagasan, serta pendapat dalam menyelesaikan project berdampak pada perkembangan kemampuan memecahkan masalah anak. Hal ini terlihat dari data perkembangan kemampuan memecahkan masalah anak pada seluruh indikator yang semula pada umumnya berada pada kriteria "belum berkembang" dan "mulai berkembang" bergeser menjadi "Berkembang Sesuai Harapan" dan "Berkembang Sangat Baik". Hal ini menunjukkan bahwa aktivitas belajar pada STEAM-PBL dapat memberikan stimulus yang tepat dalam mengembangkan kemampuan memecahkan masalah yang merupakan salah satu bagian dari aspek perkembangan kognitif anak.

\section{UCAPAN TERIMA KASIH}

Ucapan terimakasih ditujukan kepada kepala sekolah serta guru-guru tempat penelitian dilaksanakan yang telah memberikan izin serta memberi saran dan masukan sehingga penelitian ini dapat berjalan sesuai rencana. Selain itu, ucapan terimakasih juga ditujukan kepada expert yang telah bersedia memberikan justifikasinya terhadap kelayakan instrument yang digunakan.

\section{DAFTAR PUSTAKA}

Aldabbus, S. (2018). Project-Based Learning: Implementation \& Challenges. International Journal of Education, Learning and Development, 6(3), 71-79.

Astuti, I. D., Toto, T., \& Yulisma, L. (2019). Model Project Based Learning (PjBL) Terintegasi STEM untuk Meningkatkan Penguasaan Konsep dan Aktivitas Belajar Siswa. Quagga: Jurnal Pendidikan Dan Biologi, 11(2), 93. https://doi.org/10.25134/quagga.v11i2.1915

DeJarnette, N. K. (2018). Implementing STEAM in the Early Childhood Classroom. European Journal of STEM Education, 3(3), 1-9. https://doi.org/10.20897/ejsteme/3878

Dewi, M. R., Mudakir, I., \& Murdiyah, S. (2016). Pengaruh Model Pembelajaran Kolaboratif Berbasis Lesson Study terhadap Kemampuan Berpikir Kritis Siswa. The Effect of Collaborative Learning Model with Lesson Study on Student Critical Thingking. Jurnal Edukasi UNEJ, III(2), 29-33. https:/ / doi.org/10.19184/jukasi.v3i2.3526

Dyah, M. D. A., \& Setiawati, A. F. (2019). The Problem Solving Skills in Kindergarten Student Based on the Stages of Problem Solving. Jurnal Obsesi : Jurnal Pendidikan Anak Usia Dini, 3(1), 265. https:// doi.org/10.31004/obsesi.v3i1.160

Hadi G K. (2018). Pengaruh Metode Bercerita terhadap Kemampuan Mengungkapkan Bahasa Anak Usia 5-6 Tahun Di TK Pertiwi 1 Banjarsari. PG-PAUD Trunojoyo, 5(2), 131-137. https:// doi.org/10.21107/pgpaudtrunojoyo.v5i2.5441

Herawati, N. I., Yuliariatiningsih, M. S., Halimah, L., \& Mirawati. (2020). Identifikasi Prosocial Skill Anak Usia Dini dalam Project Based Learning. Prosiding Seminar Nasional Unimus, 108-114.

Imaduddin, M. (2017). Mendesain Ulang Pembelajaran Sains Anak Usia Dini yang Konstuktif Melalui Steam Project-Based. 1st Annual Conference for Muslim Scholars, 2(2), 950958.

Laboy-Rush, D. (2021). Integrated STEM education through game-based learning. 2238-2242. https:// doi.org/10.51272/pmena.42.2020-381

Lely, P., Prabawati, S., Ngurah, G., \& Agustika, S. (2020). Project-Based Learning Based On Stem ( Science, Technology, Engineering, And Mathematics ) Enhancing Students Science Knowledge Competence. Jurnal Ilmiah Sekolah Dasar, 4(4), 621-629.

Lestari, L. D. (2020). Pentingnya Mendidik Problem Solving Pada Anak Melalui Bermain. Jurnal Pendidikan Anak, 9(2), 100-108. https://doi.org/10.21831/jpa.v9i2.32034 
Lestari, S., Suarni, \& Antara, A. (2016). Pengaruh Model Pembelajaran Berbasis Proyek Terhadap Kemampuan Kerjasama Anak Usia 5-6. Pendidikan Anak Usia Dini, 4(2).

Lutfi, Ismail, \& Azis, A. A. (2017). Pengaruh Project Based Learning Terintegrasi Stem Terhadap Literasi Sains, Kreativitas dan Hasil Belajar Peserta Didik Effect of ProjectBased Learning Integrated Stem Against Science Literacy , Creativity and Learning Outcomes On Environmental Pollution. Prosiding Seminar Nasioanal BiologiDan Pembelajarannya, 189-194.

Maulidah, F., Suwatra, I. W., \& Magta, M. (2018). Pengaruh Model Pembelajaran Project Based Learning Terhadap Kemampuan Motorik Halus Anak Kelompok A Gugus VI. Pendidikan Anak Usia Dini, 6(2), 344-352. https:// doi.org/10.23887/paud.v6i2.15319

Md, M. R. (2019). 21st Century Skill "Problem Solving": Defining the Concept. Asian Journal of Interdisciplinary Research, 2(1), 64-74. https:// doi.org/10.34256/ajir1917

Mike, \& Permila. (2012). Peranan Kegiatan Bercakap-cakap Terhadap Perkembangan Kemampuan Berbahasa Anak Di Taman Kanak-Kanak Angkasa Lanud Padang. Jurnal Ilmiah PAUD, 1(5), 1-12.

Miller, A. (2017). PBL and STEAM Education: A Natural Fit. https://www.edutopia.org/blog/pbl-and-steam-natural-fit-andrew-miller

Munawar, M., Roshayanti, F., \& Sugiyanti, S. (2019). IMPLEMENTATION OF STEAM (Science Technology Engineering Art Mathematics) - Based Early Childhood Education Learning In Semarang City. Ceria (Cerdas Energik Responsif Inovatif Adaptif), 2(5), 276. https:// doi.org/10.22460/ceria.v2i5.p276-285

Nopiyanti, I., Adjie, N., \& Putri, S. U. (2020). STEAM-PBL in Early Childhood Education: Optimization Strategies for Developing Communication Skills. Advances in Social Science, Education and Humanities Research, 503, 81-86. https://doi.org/10.2991/assehr.k.201205.090

Nurjanah, A. P., \& Anggraini, G. (2020). Metode Bercerita Untuk Meningkatkan Kemampuan Berbicara Pada Anak Usia 5-6 Tahun. Jurnal Ilmiah Potensia, 5(1), 1-7. https://doi.org/10.31004/obsesi.v5i2.581

Palmer, S. B., Summers, J. A., Brotherson, M. J., Erwin, E. J., Maude, S. P., Stroup-Rentier, V., wu, H. yi, Peck, N. F., Zheng, Y., Weigel, C. J., Chu, S. Y., Mcgrath, G. S., \& Haines, S. J. (2013). Foundations for Self-Determination in Early Childhood: An Inclusive Model for Children With Disabilities. Topics in Early Childhood Special Education, 33(1), 3847. https:// doi.org/10.1177/0271121412445288

Putri, S. U. (2019). Pembelajaran Sains untuk Anak Usia Dini. Sumedang: UPI Sumedang Press.

Shieh, R. S., \& Chang, W. (2014). Fostering student's creative and problem-solving skills through a hands-on activity. Journal of Baltic Science Education, 13(5), 650-661.

Sompayrac, L. (2002). How the ARTS Benefit Student Achievement. Developmental Biology, 2008(4), 4-9. http://www.ncbi.nlm.nih.gov/pubmed/10614073

Sugiyono. (2011). Metode penelitian kuntitatif kualitatif dan R\&D. Bandung: Alfabeta.

Syaodih, E., Setiasih, O., Romadona, N. U. R. F., \& Handayani, H. (2018). Pengembangan Kemampuan Pemecahan Masalah Anak Usia Dini dalam Pembelajaran Proyek di Taman Kanak-Kanak. Jurnal Pendidikan Anak, 12(1), 29-36. https://doi.org/10.21009//JPUD.121.03

Wahyuni, S., Reswita, R., \& Afidah, M. (2020). Pengembangan Model Pembelajaran Sains, Technology, Art, Engineering And Mathemathic Pada Kurikulum PAUD. Jurnal Golden Age, 4(02), 297-309. https://doi.org/10.29408/iga.v4i02.2441

Wahyuningsih, S., Nurjanah, N. ., Rasmani, U. E. ., Hafidah, R., Pudyaningtyas, A. ., \& Syamsuddin, M. . (2020). STEAM Learning in Early Childhood Education: A Literature Review. 4(1), 33-44. https:// doi.org/10.20961/ijpte.v4i1.39855

Wortham, S. . (2006). Early Childhood Curriculum. Ohio: Pearson Merril Prentice Hall. 